\title{
A Unique Type of Student Mobility: Exploring the Dynamics of Cross-border Ethnic Education Along China-Myanmar Border
}

\author{
Xue Zhang \\ Faculty of Education, Yunnan Normal University, Kunming, China \\ Email address: \\ xuezhang_ynnu@126.com \\ To cite this article: \\ Xue Zhang. A Unique Type of Student Mobility: Exploring the Dynamics of Cross-border Ethnic Education Along China-Myanmar Border. \\ International Journal of Elementary Education. Vol. 9, No. 3, 2020, pp. 60-70. doi: 10.11648/j.ijeedu.20200903.12
}

Received: August 24, 2020; Accepted: September 14, 2020; Published: September 21, 2020

\begin{abstract}
In the context of globalization and internationalization, more and more students have the opportunities to study abroad which has aroused extensive research on the subject of student mobility. By constructing a typology of student mobility, this article sets out to broaden the analytic framework before focusing on a particular phenomenon of student mobility, namely cross-border intra-ethnic student mobility along the borderline in southwest China. Following a review of the historical progression of cross-border ethnic student mobility, the article reveals that the prevailing theory of student mobility has a limited utility when applied to cross-border ethnic student mobility, which is unique in many respects, especially due to the historically strong ethnic ties which laid the foundation for this specific type of student mobility. Using a mixed quantitative and qualitative analysis, a comparison of four different cross-border ethnic schools further illustrates the heterogeneity within cross-border ethnic education. Geographic conditions and resource constraints are the main factors influencing the functional boundaries of ethnic foundations, which further imply various solutions concerning the sustainability and evolving pathways of cross-border ethnic education. Finally, after discussing the limitations of the current research, some suggestions for future research directions are provided, highlighting the need for more reflection and investigation from multilevel perspectives.
\end{abstract}

Keywords: China-Myanmar Border, Cross-border Ethnic Education, Heterogeneity, Student Mobility, Typology

\section{Introduction}

Due to the growing globalization and internationalization, nations and regions worldwide are becoming more closely related and interdependent than ever before. As far as one country is concerned, policies made by governments at all levels, as well as market structures and resources, could influence people's choices and behaviors not only nationally but internationally, which in turn could have further impacts on policy-making process and may lead to societal changes to some extent.

For example, international students are becoming more mobile as they reach more advanced levels of education, due to which international student mobility has received increasing policy attention in recent years. The number of foreign students enrolled in tertiary education programs worldwide has exploded over the past two decades, rising from 2 million in 1999 to 5 million in 2016 [1].

For the students, studying abroad is an opportunity to access higher quality or more diverse education, which could help them acquire skills that may not be taught at home and thus allow them to gain comparative advantage in labor markets. From the host countries' perspective, the significance of mobile students exists in multi aspects, especially in the intellectual and economic benefits. Empirical evidence indicates that international students are a crucial human resource contributing to a country's talent pool and innovation system [1-4]. However, since the onset of global financial recession in 2007, many popular host countries, such as the U.S., UK, Canada, and Australia, have been focusing on attracting more and more international students as a cost-effective tool to cope with the domestic financial crisis, as international students often need to pay higher tuition fees than domestic students and have a positive impact to the local economy through their living expenses $[5,6]$. On the other hand, for the countries of origin, mobile students could be viewed either as talent lost or the potential human resources 
contributing to knowledge absorption, technology upgrading, and enablement of integration into global networks. Available evidence indicates that student mobility leads to a significant brain circulation effect by shaping deeper future international scientific cooperation networks [7].

Student mobility takes place not only internationally but also nationally, especially in some underdeveloped countries where the distribution of qualified education resources is far from equal. As a country with the largest population worldwide, over the last decades, China has been experiencing student mobility on an increasingly larger scale, accompanied by rapid industrialization and urbanization [8-10]. The number of mobile students in compulsory education rose from 16 million in 2013 to 19 million in 2017 [11]. Through heading to other countries or cities from their country of origin or hometown where they could have the opportunities to access higher education or fundamental education, most mobile students and their families may have expectations to make further movement upwards along the social ladder.

However, there is a special type of student mobility taking place along the borderline in southwest China. For example, a few groups of students from Myanmar come across the China-Myanmar border every morning to attend elementary schools located near the borderline in China and pass through the border again every night to return to their homes in Myanmar. Compared with most international students, these Myanmar students have some common motivations for school choice through mobility. Meanwhile, some particular reasons associated with the ethnic identity contribute to the cross-border student mobility, which remain an under-studied phenomenon.

As noted earlier, owing to globalization and internationalization, the types of student mobility vary. There are some commonalities underpinning the trends of international and national student mobility, while greater importance should be attached to the particularities of cross-border ethnic students in southwest China. Through literature review and a comparison of four elementary schools using data analysis, the aim of this research is to explore the historical progression of cross-border student mobility and the reasons behind this unique phenomenon. Expecting some ethnic features facilitating cross-border ethnic student mobility, it is also posited that geographic conditions and educational resources play vital roles in the evolving direction of cross-border student mobility.

The paper is organized as follows: First, a typology of student mobility is constructed as an analytic framework before providing a brief introduction of cross-border ethnicities in Yunnan Province and the current cross-border ethnic student flow patterns and the changes over time. Next, the reasons behind the dynamic progression are explored taking not only the push-pull theoretical factors but also the certain forms in the typology of student mobility into account. This will be followed by a comparison between four different elementary schools, aiming to illustrate some fundamental factors influencing the current conditions and future directions of cross-border ethnic education. Finally, after discussing the problems and limitations of cross-border ethnic education research, the future research directions in this field are proposed, aiming to encourage more reflection and cooperation on the particular trends and multiple research dimensions.

\section{Analytic Framework}

\subsection{Theoretical Issues}

Typically, authors of student mobility research tend to draw on the push-pull theory as an explanatory foundation. The driving force behind the increasing foreign enrollment includes a variety of domestic and external factors, both push (encouraging outward mobility) and pull (encouraging inward mobility) [12]. These factors can be roughly classified into three categories: (1) Educational factors, such as differentials in education capacity and education returns between destination and origin countries; (2) Economic factors of both demand and supply aspects. On the demand side, main factors include rising wealth in emerging economies within which the members of a growing middle class look for educational opportunities abroad for their children, higher economic performance in the host country, together with greater chances in the labor market after graduation. On the supply side, factors mainly contain national or institutional tuition or subsidy policies for foreign students, and university policies dealing with reduced budget by encouraging more inflows of international students, etc.; and (3) Non-economic factors, such as immigration policy and political stability in host countries, education standards and quality assurance, instructional language, as well as cultural and religious proximity.

Concerning the influential factors mentioned above, the inflows of international mobile students are supposed to be more concentrated in more developed countries, such as the United States. Likewise, mobile students pursuing fundamental education in China are more aggregated in the metropolitan cities like Beijing, Shanghai, and Guangzhou.

However, the cross-border students from Myanmar enter into schools located in rural and remote areas where the most disadvantaged Chinese students remain, as most students would rather go to schools in towns or cities if possible. Consequently, the particular cross-border student mobility in the areas along the borderline in southwest China could only be partially explained by the push-pull theory. These cross-border students from Myanmar have some unique features for they share the same ethnicity and ethnic language with their Chinese classmates. They belong to the same ethnicity historically and follow the same traditions and religious practices in their daily life. Although the ethnic groups were divided by the agreement between China and Myanmar on the delineation of borders, this has not affected the interaction and interdependence in almost every aspect of life among their communities.

As a result, the unique phenomenon of cross-border ethnic students earns a peculiar attention in the research on both cross-border and ethnic education. Furthermore, the analysis of this phenomenon should also be embedded in the social and 
educational circumstances in both adjacent countries.

\subsection{Constructing a Typology of Student Mobility}

Concerning the unique cross-border ethnic student flow patterns, for the purpose of this research, the phenomena of student mobility are categorized into four types. Drawing on a typology from a framework for studying the transnational networks of minority members as a political phenomenon [13], the author of this paper also distinguishes between student mobility via the border axis and the ethnic axis. Combining the two axes, a typology of four types of student mobility presented in Table 1 shows:

Table 1. Typology of Student Mobility.

\begin{tabular}{lll}
\hline State-Border & Ethnic Dimension & Cross-ethnic \\
\cline { 2 - 3 } Dimension & Intra-ethnic & Intra-border, cross-ethnic student mobility \\
\hline In-border & Intra-border, intra-ethnic student mobility & Cross-border, cross-ethnic student mobility \\
\hline
\end{tabular}

Source: Adapted from Menahem (2010).

1) Intra-border, intra-ethnic student mobility, involving students belonging to the same ethnic group that attend schools within the state's territory. Much of the research about school choices fits into this category.

2) Intra-border, cross-ethnic student mobility, referring to students of one ethnic group attending schools where most students belong to another ethnic group within the borders of the state. Numerous studies of multilingual and multicultural education fall into this category.

3) Cross-border, intra-ethnic student mobility, involving students travelling across state borders to another country where most citizens have the same ethnicity as they do. The particular flow pattern on which this research is focused belongs to this category.

4) Cross-border, cross-ethnic student mobility, referring to students that seek education in another country where most citizens have different ethnicities. Most studies on international students could be classified into this category.

The aforementioned classification of student mobility is important because it could help distinguish different influential factors on each kind. It is obvious that push-pull theory is more relevant for discussions in category 1 and 4 . However, push-pull theory has limited utility when it comes to category 2 or 3 due to the extra variable, ethnicity, which constructs intangible but solid foundations impacting greatly on student mobility.

As a reflective discussion on the prevailing student mobility theory, this research will focus on the third mobility type, cross-border intra-ethnic (hereinafter referred to as cross-border ethnic) student mobility, aiming to answer two questions: What is the historical evolvement of cross-border ethnic student mobility in China-Myanmar border areas? What are the impacts and consequences of cross-border ethnic education?

\section{Cross-Border Ethnicities and Cross-Border Ethnic Student Flow Patterns}

\subsection{Cross-Border Ethnicities and Cross-Border Ethnic Interactions}

Along the land boundary lines totaling $22,000 \mathrm{~km}$ in China,
$4,060 \mathrm{~km}$ (accounting for nearly 20\%) is located in eight minority autonomous prefectures in Yunnan Province bordering three countries-Myanmar, Laos, and Vietnam-including 11 national-level and 9 provincial-level ports, as well as over 100 border trade zones and temporary trails. Being home to 25 ethnic minorities and the most diverse region in China, Yunnan shares a border of 1,997 km, $701 \mathrm{~km}$, and 1,353 km with Myanmar, Laos, and Vietnam, respectively. It is also noteworthy that 16 of the 25 ethnic groups are identified as cross-border ethnicities, including Zhuang, Dai, Miao, Yao, Yi, Jingpo, Buyi, Hani, Lisu, Lahu, Achang, Dulong, Nu, Wa, Buliang, and Deang ethnicity. Some of them are distributed mainly within the Yunnan Province, while others reside in neighboring countries.

From the national and political point of view, cross-border ethnicities belong to different countries depending on in which country they live. However, from the historical and cultural perspectives, they are more likely seen as members of similar communities, for they have shared the same traditions, languages, cultures, and religions for a much longer period of time than they have had different national identities.

Based on the ethnic and cultural underlying foundations, cross-border ethnicities have long-lasting historic and solid social networks over the politically symbolic border. The diverse interactions passing through the borderlines among cross-border ethnicities range from business and trade, labor force mobility, transnational marriages, and religious communication to transnational cooperation on national security or drug control projects. Due to their particular geographic and demographic features, the cross-border multi-level connections are markedly different from the general communications within countries and ethnicities. Furthermore, due to the sensitive implications for diplomacy and national defense, national and ethnic identity, culture and religion, research on cross-border ethnicities has always been a highly debated issue. At the same time, systematic in-depth studies are still rare on account of the particularity and complexity of the research phenomenon.

\subsection{Current Trends in Cross-Border Ethnic Student Flows}

In order to explore the interaction landscape of cross-border ethnicities, I would take current trend of cross-border ethnic 
student educational flow as a departure point. According to the available records, cross-border ethnic students first started entering the classrooms in neighboring countries in the 1980s [14]. As China was moving into a new era of reform and greater openness, along with the open frontier management and rising cross-border trade, a few Myanmar students came to Chinese elementary schools in order to gain some communicative abilities in Chinese that would facilitate their future career in cross-border business. Based on the statistics from the Education Department of Yunnan, prior to 2011, 5,057 foreign students studied in Yunnan at compulsory education stage, which is a $64.13 \%$ increase from 2,086 in 2008. Most of them (97\%) came from the neighboring countries-Myanmar, Vietnam, and Laos-and $85.22 \%$ of these children studied in elementary schools (Figure 1). From the geographic point of view, as Figure 2 shows, the longer borderline the region has, the greater number of students would be studying there [15]. For example, Dehong Prefecture which has the longest borderline accounts for the largest proportion of foreign students in fundamental schools in Yunnan Province.

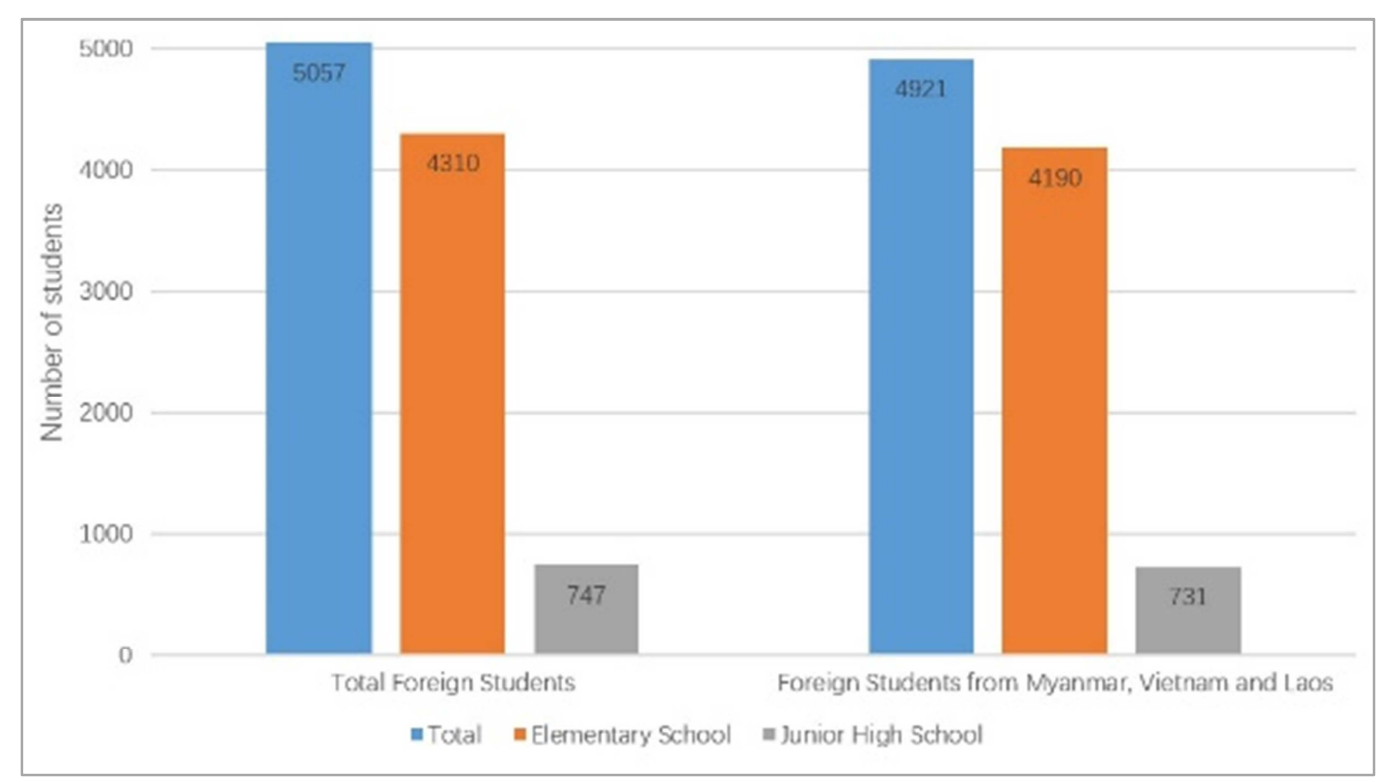

Figure 1. Foreign students in fundamental schools in Yunnan, 2011. Source: He \& Liu (2013).

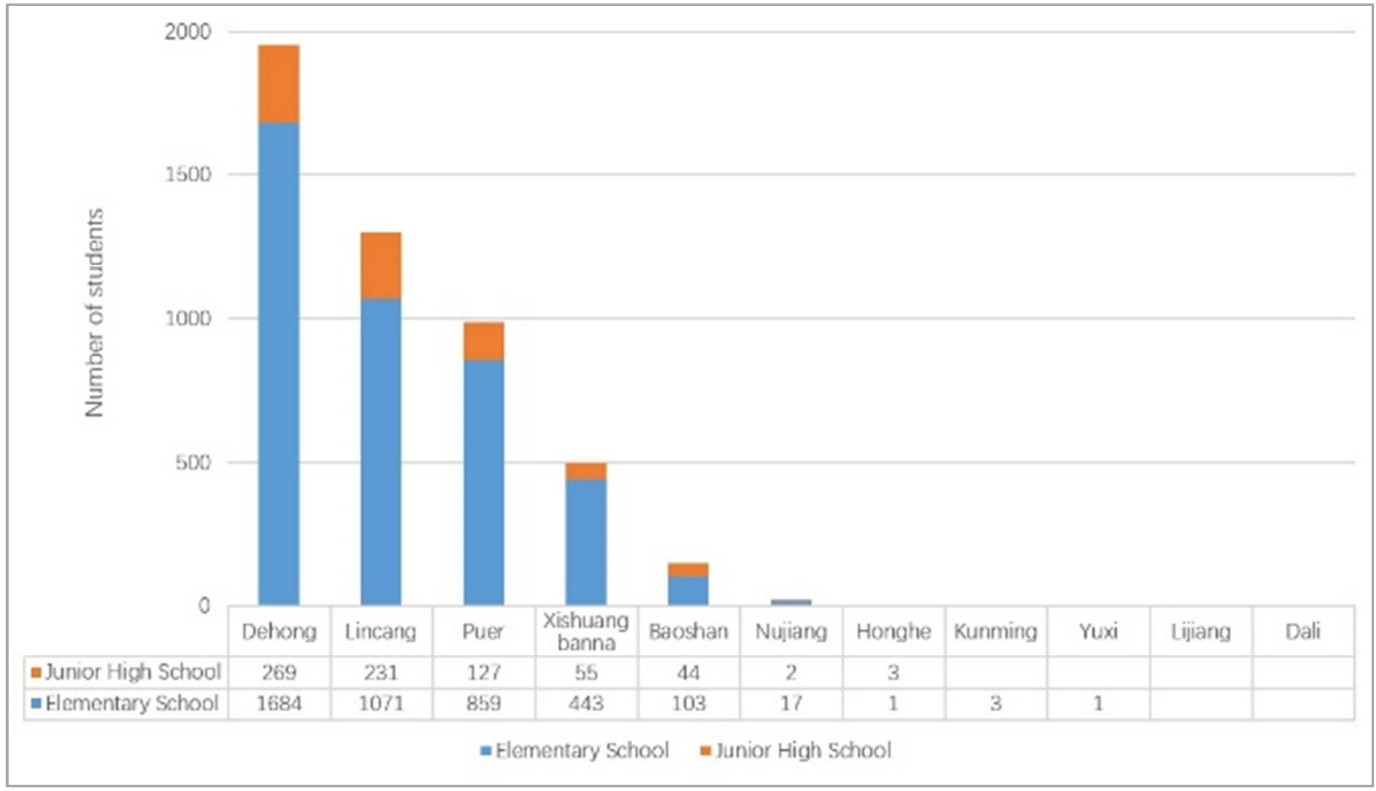

Figure 2. The distribution of students from Myanmar, Vietnam and Laos in fundamental schools in Yunnan, 2011. Source: He \& Liu (2013).

\subsection{Changes in the Cross-Border Ethnic Student Flow Patterns over Time}

Nowadays, it seems that more and more cross-border ethnic students from Myanmar flow into schools located in nearby cross-border areas in Yunnan Province, but this was not always the case. Prior to 1990s, cross-border ethnic Chinese students came across the borderline to Myanmar to attend 
classes as they could not afford the tuition fees in China's elementary schools [16]. Although they were aware of the lower quality of schools in Myanmar, affordability was the most important influential factor in their educational choices. At that time, Chinese central government's financial resources were too limited to implement free compulsory education nationwide. Consequently, the students and their families needed to share the education costs, which were once a huge burden especially for the disadvantaged groups.

This phenomenon triggered numerous newspaper and magazine reports, prompting some governmental departments of Yunnan Province to work together to issue some policies as a response. Yunnan Provincial Ethnic Affairs Commission, Education Department, and Finance Department jointly promulgated a new educational regulation in 2000, which made elementary education schools free for students living along the cross-border areas in Yunnan [16].

After that, not only the Chinese students who had attended schools in Myanmar due to affordability came back to schools in China but some Myanmar students crossed the border to attend elementary schools in borderline areas of China [16, 17]. At first, the number of cross-border foreign students in Yunnan was relatively small. Owing to globalization and urbanization, more and more young adults and children from rural Yunnan went to cities or towns to make a living or get access to high-quality education. Moreover, a large number of Myanmar workers and students continuously came to border areas to do business or to enjoy a free and comparatively higher quality education. Consequently, the flow patterns became one-way and more extensive compared with two-way and sporadic status in the past.

\subsection{Exploring the Reasons Behind the Changes in Flow Trends}

As indicated by the typology of student mobility presented previously, each type of student mobility has its own distinguishing features despite some common foundations. For instance, the two student flow patterns denoted as Type 3 and Type 4 have similarities as well as differences.

Prior to 2000, the outflow of Chinese students to Myanmar was mostly driven by economic reasons and the direction of flow was temporary. After the implementation of free education policy in the Yunnan border area, all Chinese students came back since there were no obvious benefits of educational quality or future employment competence from remaining in Myanmar schools. After that, Myanmar students choose to come to elementary schools in Yunnan because they can access higher quality education at no cost, while they rarely have the opportunity to go to school in their own country due to the turbulent situation. Moreover, the acquisition of literacy in Chinese would strengthen their competitiveness in the border trade labor market. The bidirectional flow seems to be in accordance with the push-pull theory.

Still, the trends of cross-border ethnic student flow should also be attributed to many unique factors that are not included in the general push-pull analytical framework. The most crucial element is their natural ties based on the same ethnic origin, tradition, language, and culture. These social networks have been constructed by multi-level interactions within the ethnic group during a very long history even before the existence of borderline, which made them cross-border ethnic group.

The multi-level interactions among cross-border ethnic groups could be influenced but can never be stopped by the politically symbolic borderline. Moreover, because of two different regimes resulting in opportunity and resource gaps between the two sides, cross-border ethnic groups come and go over the borderline to gain a comparative advantage and thus maximize their living conditions on the underlying foundation of their invisible but solid multi-level social networks. For the cross-border ethnic student flow trends, the intra-ethnic social network is the prerequisite for students at both sides to make choices. Surely, the convenient geographic position is another vital factor making the cross-border flow even easier than travelling to other domestic places. Besides, the cross-border labor force mobility and cross-border marriage are some other causes leading to cross-border student flow.

\section{Research Design}

Realizing the unique features and academic value of cross-border ethnic student mobility, our research team initiated field trips to border areas in order to keep up with the latest situation and launch more in-depth investigations. From November 2018 to April 2019, our research team took field trips to two counties, Cangyuan and Ruili, both of which are located within the China-Myanmar border areas in Yunnan Province. We visited four elementary schools and one middle school in Cangyuan, as well as one kindergarten, nine elementary schools, and one high school in Ruili, where all cross-border ethnic students come from Myanmar. During the field trips, we undertook some informal interviews with principals, teachers, and students, along with classroom observations. Besides, we collected data on some schools' fundamental statistics, such as the number, age, nationality, and ethnicity of both students and teachers. For the purpose of comparison, the analyses presented here focus on four elementary schools of which the data is available and comparable.

The comparisons and discussions of these four schools rely primarily on informal interviews with principals and teachers of these institutions, one in Cangyuan and three in Ruili, respectively. Through describing and analyzing statistics, four schools are compared from a variety of aspects, such as school scale, student nationality, student-teacher ratio, and the ethnic composition of both teachers and students. All data was gathered by the schools in 2018, at the beginning of the 2018-2019 school year.

Using a mixed qualitative and quantitative analysis, various scenarios in terms of cross-border ethnic education are 
presented in this article, aiming to synthesize the commonality and heterogeneity from the comparison of four elementary schools. By doing so, the author intends to establish basic facts about the particular phenomenon, before exploring the dynamic progression of cross-border ethnic student mobility and its impacts on school operation as well as its potential evolving directions in the future.

\section{A Comparison among Four Cross-Border Elementary Schools}

In this section, a detailed comparison among the four chosen elementary schools will be presented, facilitating in-depth understanding and discussion on cross-border ethnic education.

\subsection{Four Schools with Cross-Border Ethnic Students}

\subsubsection{School C}

A small-scale elementary school (School C) will be used as a typical illustration. Thirty-nine students are studying at School C, which is located in a relatively isolated village of Cangyuan county near the China-Myanmar border. At 27, almost $70 \%$ of these students are coming from Myanmar, and they climb a mountain for about two hours in the morning to go to school and return home every night from Monday to Friday during the school year. The other 12 students are Chinese students living in the village where the school is located.

All of these students have the same ethnic identity, Wa, and can communicate with each other in the same ethnic language, Wa language. It is not easy to tell the difference between their countries of origin due to their similar appearance. Moreover, the content they learn in the classroom and the activities in which they participate on campus are exactly alike. Though some of these Myanmar students knew very limited Chinese at the beginning, they could gradually acquire basic literacy with the help of their teachers who are also Wa people and would explain the course content using Wa language if necessary. What is happening here illustrates a typical cross-border intra-ethnic student mobility pattern. By taking advantage of their ethnic foundations, Myanmar students rely on their ethnic language and further extend their original language boundary to the Chinese realm, which is also one of the most important goals of studying in China.

However, there are also some negative aspects in the current situation. Teachers shared that some of their Myanmar students are over the required age because of their limited Chinese proficiency. This means that, although some elder students completed elementary education in their own country, they need to retake the courses from grade one to learn Chinese. Consequently, compared to their Chinese classmates, Myanmar students are two years older on average and their age has a wider range.

From the principal's perspective, the enrollment of Myanmar students is not a burden for school operation because the educational appropriation is allotted based on the number of students, including those from Myanmar. The principal was concerned the most with the management of these Myanmar students, since low drop-out rate is the most vital indicator for qualifying as a compulsory school. As Myanmar students are vulnerable to Myanmar's turbulent situation and may be asked to stop going to school and join the army if necessary, the resulting high drop-out rate would potentially disqualify the school. This small school could be regarded as the epitome of cross-border student education in Yunnan Province in recent years.

\subsubsection{School R1, R2 and $R 3$}

The three remaining schools (denoted as R1, R2, and R3) will be examined next to illustrate various scenarios in terms of cross-border ethnic education. Unlike School C, these three schools are located in Ruili County, a cross-border trade center. As shown in Table 2, the total student numbers range from 104 to 1,048 and the percentage of Myanmar students is much lower than in School C (28\%, 13\%, and 20\% in School R1, R2, and R3, compared to $69 \%$ in School C). On the other hand, these three schools have a much higher student-teacher ratio (20.8, 18.9, and 21.8, respectively, compared to 6.5 in School C). Not surprisingly, Myanmar students might be less desirable to schools in Ruili due to limited teacher resources, because student-teacher ratio should not exceed 21 in accordance with the regulation of Ministry of Education in China [18].

Table 2. A Comparison among Schools $C, R 1, R 2$, and $R 3$.

\begin{tabular}{|c|c|c|c|c|c|c|c|c|c|c|c|c|}
\hline County & Cangyuan & Ruili & & & & & & & & & & \\
\hline School & $\mathrm{C}$ & $\mathrm{R} 1$ & & & $\mathrm{R} 2$ & & & & & $\mathrm{R} 3$ & & \\
\hline Total number of students & 39 & 104 & & & 246 & & & & & 1048 & & \\
\hline Myanmar students (\%) & $\begin{array}{l}27 \\
(69 \%)\end{array}$ & $\begin{array}{l}29 \\
(28 \%)\end{array}$ & & & $\begin{array}{l}31 \\
(13 \%)\end{array}$ & & & & & $\begin{array}{l}217 \\
(20 \%)\end{array}$ & & \\
\hline Teachers & 6 & 5 & & & 13 & & & & & 48 & & \\
\hline Student-teacher ratio & 6.5 & 20.8 & & & 18.9 & & & & & 21.8 & & \\
\hline Student ethnicity (\%) & $\begin{array}{l}\text { Wa } \\
(100 \%)\end{array}$ & $\begin{array}{l}\text { Dai } \\
(86 \%)\end{array}$ & $\begin{array}{l}\text { Han } \\
(12 \%)\end{array}$ & $\begin{array}{l}\text { others } \\
(2 \%)\end{array}$ & $\begin{array}{l}\text { Han } \\
(40 \%)\end{array}$ & $\begin{array}{l}\text { Dai } \\
(24 \%)\end{array}$ & $\begin{array}{l}\text { Deang } \\
(17 \%)\end{array}$ & $\begin{array}{l}\text { Jingpo } \\
(16 \%)\end{array}$ & $\begin{array}{l}\text { Others } \\
(3 \%)\end{array}$ & $\begin{array}{l}\text { Dai } \\
(89 \%)\end{array}$ & $\begin{array}{l}\text { Han } \\
(10 \%)\end{array}$ & $\begin{array}{l}\text { Others } \\
(1 \%)\end{array}$ \\
\hline $\begin{array}{l}\text { Myanmar student } \\
\text { ethnicity }(\%)\end{array}$ & $\begin{array}{l}\text { Wa } \\
(100 \%)\end{array}$ & $\begin{array}{l}\text { Dai } \\
(100 \%)\end{array}$ & & & $\begin{array}{l}\text { Han } \\
(81 \%)\end{array}$ & & $\begin{array}{l}\text { Dai } \\
(16 \%)\end{array}$ & & $\begin{array}{l}\text { Jingpo } \\
(3 \%)\end{array}$ & $\begin{array}{l}\text { Dai } \\
(99 \%)\end{array}$ & $\begin{array}{l}\text { Han } \\
(0.5 \%)\end{array}$ & $\begin{array}{l}\text { Jingpo } \\
(0.5 \%)\end{array}$ \\
\hline Teacher ethnicity (\%) & $\begin{array}{l}\text { Wa } \\
(100 \%)\end{array}$ & $\begin{array}{l}\text { Han } \\
(60 \%)\end{array}$ & & $\begin{array}{l}\text { Dai } \\
(40 \%)\end{array}$ & $\begin{array}{l}\text { Han } \\
(62 \%)\end{array}$ & & $\begin{array}{l}\text { Dai } \\
(38 \%)\end{array}$ & & & $\begin{array}{l}\text { Han } \\
(50 \%)\end{array}$ & $\begin{array}{l}\text { Dai } \\
(38 \%)\end{array}$ & $\begin{array}{l}\text { Others } \\
(12 \%)\end{array}$ \\
\hline
\end{tabular}

Compared with School C, schools R1, R2, and R3 have 
students. Consequently, teachers' ethnic composition could not fully match that of Myanmar students who may be exposed to disadvantages if they are in need of assistance in their ethnic languages. Taking schools R1 and R3 as an example, the ethnicity of most Myanmar students is Dai, while no more than $40 \%$ of teachers have that ethnicity. It is even more problematic that most ethnic teachers are incapable of using their own ethnic language and could speak only Chinese. Those Dai students from Myanmar could take advantage of their ethnic foundations as those in School $\mathrm{C}$ to facilitate their learning, as long as there is a matching ethnic composition among the teachers. Alternatively, these cross-border Dai students may be at a disadvantage if they know little Chinese before starting school. In such circumstances, most principals and teachers in these schools proposed urgent demands for preschool where Myanmar students could learn Chinese as early as possible. Likewise, the age of Myanmar students in schools R1, R2, and R3 has a tendency similar to that in School C. What's more, the average age of Myanmar students is higher than that of their Chinese peers and has a much wider range. Consequently, elder Myanmar students are more likely to leave school due to the difficulty in getting along well with their younger classmates, as some principals and teachers observed. For schools R1, R2, and R3, student mobility could not be classified under only one type, because it has features of both cross-border intra-ethnic and in-border cross-ethnic student mobility. This overlap makes the circumstances more complicated.

\subsection{Result and Discussion}

Comparison of similarities and differences among the four elementary schools in two counties reveals that two main factors - geographic condition and resource constraint - carry considerable weight in determining whether Myanmar students are desirable or vulnerable from the school's perspective, both of which are interrelated and interdependent to a great extent.

Geographic position reflecting the social changes and student mobility in the context of urbanization is highly associated with the available space for cross-border ethnic students. Schools like School C that are located in remote areas from which Chinese students and their families tend to move outward for a better education and life may offer adequate enrollment opportunities for cross-border ethnic students. Conversely, schools like R1, R2, and R3 that are located in relatively prosperous regions, where Chinese students even relocate from other counties or cities, are less likely to enroll more Myanmar students. There is no doubt that schools would give priority to the educational needs of Chinese students.

Resource constraint is another vital factor that is highly related to geographic conditions. Financial and teacher resources greatly affect the potential for cross-border ethnic student enrollment. Schools like School C have a much simpler pattern and comparatively more abundant financial and human resources for accepting students from Myanmar, and the ethnic composition of teachers is suitable for supporting cross-border ethnic student learning. However, schools like R1, R2, and R3 with more diverse and complex modes of operation would be more cautious about the number and quality of Myanmar students due to the limited teacher resources. Myanmar students would be more likely to be left behind or even drop out from school if the educational resources needed for supporting their study in Chinese are lacking, which would in turn make schools more reluctant to receive Myanmar students in consideration of two essential school assessment indicators, student performance and drop-out rate.

From the perspective of student mobility typology, it can be concluded that the particularity of cross-border ethnic student mobility and the heterogeneity within cross-border ethnic education coexist. Compared with other types of student mobility, cross-border ethnic student mobility could only be partially explained by the prevailing push-pull theory, as it has its own particular features mostly derived from ethnic foundations. After zooming in on the details of four individual schools, various scenarios had been presented and cross-border ethnic education turns out to be heterogeneous. School $\mathrm{C}$ has a unitary ethnic group and can be classified as Type 3, and in such circumstances, the ethnic foundation could work from access to process. However, schools R1, R2, and R3 have more complicated modes of operation, and thus have characteristics of both Type 2 and Type 3, due to which the ethnic foundation could only works in a comparatively limited period. Cross-border ethnic students entering into schools like R1, R2, and R3 basically rely on their ethnic social networks. However, during the educational process, their ethnic ties rarely work due to the insufficiency of ethnic teachers. The heterogeneity stemming from geographic conditions and resource constraints manifests in various functional boundaries of ethnic foundations in cross-border ethnic education.

In brief, offering more teacher-training for bilingual education or initiating more preschools for Chinese learning for Myanmar students could possibly serve as solutions to these problems. It is evident that teachers possessing adequate bilingual education and cultural comprehension are especially essential for cross-border ethnic students, but teachers being capable of bilingual education are far from enough both now and in the future. It is acknowledged that preschools for Myanmar students could be used as a substitution strategy if the number of qualified ethnic teachers is insufficient. As some principals and teachers shared, Myanmar students could understand Chinese very well if they had been in preschool a year before entering elementary school.

\section{The Future Direction of the Cross-Border Ethnic Education Research}

Since the cross-border ethnic student mobility has its own particularity, as well as the heterogeneity within cross-border 
ethnic education, it is of great significance to note that the heterogeneity and the reasons behind it are the keys for unlocking the particularity and complexity of cross-border ethnic education issues. However, the multi-dimensional heterogeneity of research objects has rarely been examined in extant studies. In this section, after discussing the limitations of pertinent literature on this subject, four dimensions of heterogeneity are deconstructed respectively.

\subsection{Existing Research Problems and Limitations}

Authors of extant studies basically came to the same conclusion concerning the reasons underlying cross-border student flow trends. Some researchers focused more on the angles of national security and ethnic identity [19-21]. Others have provided statistical descriptions of the scale and distribution of Myanmar students studying in Chinese schools $[22,23]$. Yet, some others [24, 25] put more emphasis on case studies of individual schools to investigate the ways to improve policies so that the Myanmar students could get easier access to Chinese schools and receive the same treatment as Chinese students. It is also proposed that Myanmar students should have a channel to further their education in schools of higher levels in China and the opportunity to take the Chinese college entrance examination [23]. Most of these researchers tend to postulate that Myanmar students should be treated equally, which should also be the expectation and goal of policy-making.

However, existing research has its own limitations, most notably the unilateral perspective on the phenomenon of cross-border student flow. To put it differently, we know very little about the views and opinions on the other side of the borderline, from the upper level government to the lower level of student families, on the student inflow or outflow across the border. In the 1990s, the outflow of Chinese students was regarded as a social crisis that attracted extensive attention especially from the local government, which made elementary schools free to all students as a response. Now that the same outflow trend has occurred, the standpoint and response of Myanmar central and local governments should be examined. Indeed, the Myanmar students who now study in Chinese schools have many educational benefits. Nonetheless, if research cannot proceed into higher and wider analytical dimensions, the conclusions and measures drawing on the narrow and biased discourse system would not lead to mutual beneficial cooperation patterns in both education areas and national relations.

\subsection{National Heterogeneity}

Three countries - Myanmar, Laos, and Vietnam — share the border lines with Yunnan Province. As noted in pertinent literature, these neighboring countries have diverse attitudes concerning cross-border education.

As an underdeveloped country, Myanmar is defined as one of the least developed countries by the United Nations. Still, Myanmar government thinks highly of the fundamental education and every student needs to go to Myanmar public schools to learn Burmese. For some historically political reasons, teaching Chinese language was forbidden in Myanmar public schools [16]. As a result, Chinese learning schools could only apply for approval in the name of religious temples as tutoring schools. Students, especially overseas Chinese children who wanted to learn Chinese, had to give up Myanmar public school or learn Chinese after the school time.

It is evident that Myanmar government did not adopt an open educational policy and put more emphasis on Burmese learning. On account of domestic political conflicts, the areas lying along the Myanmar-China border in Myanmar have been continuously affected by social turbulence, which is why more and more students seek education in Yunnan, since their local schools are in an unstable and unsustainable situation.

But for now, China is Myanmar's largest trading partner as well as the biggest investment source country. At the same time, Myanmar migrant population is the fourth largest foreign population in China and most of them settled in Yunnan Province [26]. Yet, despite the increasingly intense communication and interaction between Myanmar and China, the policy orientation concerning the domestic fundamental education and cross-border education in Myanmar is still not clear, which hinders in-depth research on effective cross-border education policy-making to a great extent.

As another country defined as one of the least developed countries by the United Nations, Laos has adopted a positive attitude and open policies promoting education cooperation programs with various educational institutions in Yunnan Province. Laos government has attached great importance to occupational skills training through educational cooperation programs with Yunnan Province. Government-led strategy put more emphasis on human resources, which are in urgent need of social and economic development. Nonetheless, the fundamental education status in Laos domestic and cross-border areas is largely unclear. Only a few studies have been reported that Laos government gave permission to cross-border students if they intended to go to school in China [17].

Vietnamese government implemented special education policy on the border areas in the 1990s. As a result, not only students and teachers in border schools could have free education and higher salaries, but students' families could also have subsidies. These preferential terms even attracted residents living nearby in Yunnan and Guangxi provinces, many of whom emigrated to Vietnam $[16,19,15]$. Vietnamese government intends to find a competitive balance on education and other issues within the border area [27]. Consequently, extant research has shown that the inflow of students from Vietnam accounted for the smallest proportion compared to the other neighboring countries [28].

As shown above, national heterogeneity should be an important dimension when interpreting different scales of and reasons behind cross-border ethnic student flow choices. If we know little about the education policies in these adjacent countries, it may be very hard to make a breakthrough at the more objective and comprehensive research achievements. 


\subsection{Regional Heterogeneity}

As Yunnan is the most culturally diverse province having the greatest number of minorities, its border areas present regional heterogeneity due to geographic or ethnic features and social economic status.

For example, due to the development of local economy, many students are more likely to drop out of school at an early stage to take advantage of labor market opportunities. As what they learned in school could not be transformed to income, the view that schooling is useless became prevalent [29]. Still, in some Theravada religious areas, students choose to receive religious education in monasteries in Myanmar or Vietnam [30]. As another example, since the end of the 19th century, a cross-border Christianity culture belt had been constructed from north to south along the China-Myanmar border [31, 32]. The highly frequent mutual mobility and cultural communication based on the same faith has shaped the external environment and internal psychological mechanisms relating to the cross-border ethnic student flow trends. Yet, the dimension of regional heterogeneity has not been systematically studied as a part of the cross-border ethnic education research.

As the comparison of four elementary schools mentioned above revealed, schools in Cangyuan and Ruili illustrate obvious diversity because of their geographic location, which is also highly related to the dynamics of economy and population. By this token, cross-border ethnic education may need to address the dual heterogeneity of both country and region simultaneously. This kind of analytical research has not yet been conducted.

\subsection{Pupil Heterogeneity}

Extant research has not yet paid close attention to the heterogeneity among the groups of cross-border ethnic students in their educational choices, expectations, and achievements. As previously mentioned, some foreign students coming across the border to go to Chinese schools are driven by economic factors concerning their families' budget constraints. Others may be motivated by cultural factors, especially the overseas Chinese children who would go to Chinese school to learn more about Chinese culture even if it is not free of charge.

The expectations of education also vary, as some students seek to acquire basic Chinese literacy in order to get a job in border trade business, while others may have long-term goals of furthering their education to higher levels in China [33].

In addition, research has shown that foreign cross-border ethnic students study harder than do the domestic ones, as they could gain significant advantage in their domestic labor markets [21]. After gaining education in the same class, cross-border ethnic students' educational outcomes emerged to be great disparities because of their different nationalities. Specifically speaking, Myanmar students could live a better life in Myanmar after graduation due to their acquisition of Chinese, while Chinese students may still be at a disadvantage for they do not have any competitiveness compared to other
Chinese peers. This is also something worthy of deep reflection and exploration.

Pupil heterogeneity requires discussions on the ways to educate foreign students to meet their various educational needs, as well as the approaches to cultivate domestic student who could also have competitive advantages after graduation from border schools.

\subsection{School Heterogeneity}

The border areas of both countries are located in the marginal zones far away from the political and economic centers where the cross-border ethnic student mobility has an extremely different underlying foundation and practical patterns. As the main receivers of foreign cross-border ethnic students, schools in border areas in Yunnan are confronted with more severe challenges than schools located elsewhere.

As was shown in this work, the core of underlying foundation of cross-border ethnic student flow is the commonness of ethnic culture and language, which means that teachers in these receiver schools should be adequately trained in bilingual education and cultural comprehensions. It is also worth noting that schools in Cangyuan and Ruili have different geographic positions and resource constraints. They are confronted with various problems and need to seek corresponding solutions. For School C, enhancement of bilingual education could be a sustainable method, while for schools in Ruili, provision of more preschools may be a suitable substitute for recruiting more bilingual ethnic teachers.

Last but not least, since almost all Chinese compulsory schools are evaluated by a set of unified standards, border schools may need some flexible evaluation criteria due to their unique composition of students and particular function of education. Border schools should be given more opportunities to explore their own distinctive patterns of education beneficial to cross-border ethnic students, both now and in the future.

\section{Conclusion}

In this article, a particular phenomenon of student mobility is presented and discussed through constructing a typology of student mobility. The comparison between various types of student mobility using two axes of state-border and ethnic dimensions could contribute to enriching the analytic framework in the field of student mobility research. Compared to other categories, the flow trends and reasons behind cross-border intra-ethnic student mobility deserve more multidisciplinary exploration and cooperation. The driving forces behind cross-border intra-ethnic student mobility should be attributed to not only the prevailing push-pull theoretical factors, but also some historically solid fundamental networks knitting cross-border ethnicities together within multi-level and multi-dimensional aspects.

The research presented here went a step further to investigate the heterogeneity within cross-border ethnic education through the lens of individual schools. The 
comparison of four elementary schools reveals that geographic conditions and resource constraints may be the main influential factors which have enormous impacts on not only the functional boundaries of ethnic foundations but also the potential policy directions pertaining to cross-border ethnic education.

However, there are still plenty of limitations in current research, since the particularity and complexity of cross-border ethnic student mobility requires long-term observation and in-depth exploration in this age of globalization and regional integration. It is still unclear how all the stakeholders in this scenario would interpret what is happening and what they expect to happen in the coming years. Not only the phenomenon and essence of cross-border intra-ethnic student mobility, but also the reasons behind this dynamic progression and the influences on both students and societies in the future are worthy of being analyzed more deeply and deliberately.

\section{References}

[1] OECD. (2018). Education at a Glance 2018: OECD Indicators. Paris: OECD Publishing. http://doi:10.1787/eag-2018-en.

[2] Abella, M. (2006). Global competition for skilled workers and consequences. In C. Kuptsch \& E. Pang (Eds.), Competing for Global Talent (pp. 11-32). Geneva, Switzerland: ILO.

[3] Findlay, A. M. (2011). An assessment of supply and demand-side theorizations of international student mobility. International Migration, 49 (2), 162-190.

[4] Wit, H. D. (2015). Recent trends and issues in international student mobility. International Higher Education, 59, 13-14.

[5] Choudaha, R., \& Chang, L. (2012). Trends in international student mobility. Accessed 22, December 2012, from https://papers.ssrn.com/sol3/papers.cfm?abstract_id=2184988.

[6] Choudaha, R. (2017). Three waves of international student mobility (1999-2020). Studies in Higher Education, 42 (5), 825-832.

[7] Appelt, S., Beuzekom, B. V., Galindo-Rueda, F., \& Pinho, R. D. (2015). Which factors influence the international mobility of research scientists? In Geuna, A. (Eds.), Global Mobility of Research Scientists (Ch. 7, pp. 177-213). Salt Lake City, Utah: Academic Press.

[8] Xiong, C. (2009). "Words-up-moving": The new trend of China's rural education since late 1990s. Sociological Studies, 5, 110-245.

[9] Wu, Z., \& Shi, N. (2011). The trends and policy issues for rural school layout and adjustment in the last decade in China. Educational Research, 7, 22-30.

[10] Liu, X. (2018). Rural education changes in the forty years of reform and opening up from the perspective of urbanization. Research in Educational Development, 17, 64-70.

[11] Li, N. (2018, October 8). Zhongguo Youduoshao Liudong Er'tong He Liushou Er'tong [How many migrant children and left-behind children are there in China]. Accessed 8, October 2018, from http://www.sohu.com/a/258196622_100291829
[12] UNESCO (2013). The International Mobility of Students in Asia and the Pacific. Retrieved from http://unesdoc.unesco.org/images/0022/002262/226219E.pdf

[13] Menahem, G. (2010). Cross-border, cross-ethnic, and transnational networks of a trapped minority: Israeli Arab citizens in Tel Aviv-Jaffa. Global Networks, 10 (4), 529-546.

[14] Hu, Y., Li, Y., \& Guo, A. (2013). Myanmar students in Frontier Elementary School in Yunnan. Accessed 27, February 2013, from

http://cnews.chinadaily.com.cn/2013-02/27/content_16262201 2.htm

[15] He, Q., \& Liu, H. (2013). Analysis on the education situation for foreign students of cross-border ethnic groups in Yunnan. Journal of Yunnan Agricultural University, 7 (1), 77-82.

[16] Yin, H. (2003). The educational competition on the frontier. Journal of Nanfengchuang, 11, 50-52.

[17] He, Y. (2010). On rising and development of the cross-border ethnic education in Yunnan and peripheral countries. Around Southeast Asia, 6, 40-44.

[18] Ministry of Education of People's Republic of China. (2001). Guanyu Zhiding Zhongxiaoxue Jiaozhigong Bianzhi Biaozhun de Yijian [Opinions on the establishment of standards for the staffing in primary and secondary schools]. Accessed 8, October 2001, from http://www.moe.gov.cn/jyb xxgk/moe_1777/moe 1778/2010 01/t20100129_180778.html

[19] He, Y., \& Gao, H. (2010). The education issues of Yunnan cross-border ethnic groups in the perspective of cultural safety. Journal of Yunnan Normal University, 42 (4), 35-41.

[20] Li, F. (2016). Implementation challenges for the education policy for international students receiving China's compulsory education in the border areas and possible solutions: A case study at Dehong Dai-Jingpo Autonomous Prefecture in Yunnan Province. Journal of Yunnan Minzu University, 33 (6), 140-147.

[21] Huang, X., \& Liao, S. (2017). On the construction of national identity consciousness in cross-border areas of Yunnan-Ruili elementary school as an example. Journal of Honghe University, 15 (4), 125-128.

[22] Luo, Q. (2017). Development of basic education in areas of transboundary ethnic groups in Lincang Prefecture: Current situation and solutions. Journal of Chuxiong Normal University, 32 (6), 32-36.

[23] Wang, Y., Yin, L., \& Dong, S. (2017). A study on Burmese students' cross-border admission in Sino-Burmese borderlands-Based on the survey from the Prefecture of Dehong in Yunnan Province. Academic Exploration, 12, 140-145.

[24] Liu, Q., Liang, L., Liang, S., Ge, X., Zhang, Y., Wang, H., \& Wu, Y. (2011). The educational frontier on southwest border: A research on the current situation of the country gateway schools of Yunnan. Journal of Guangxi Normal University, 47 (6), 104-109.

[25] Zhu, J., \& Song, K. (2014). Thoughts on developing elementary education in cross-border ethnic areas-A case Study of Dehong Prefecture in Yunnan. Journal of Baoshan College, 33 (6), 75-78. 
[26] Tian, S. (2017). Means of livelihood and living space of registered Burmese nationals living in the towns in the Sino-Burmese border area-Based on an investigation in Ruili, Yunnan. Journal of Ethnology, 1, 75-83.

[27] He, Y., \& Gao, H. (2012). Soft power of the cross-border ethnic education in Yunnan. Journal of Yunnan Nationalities University, 29 (6), 126-131.

[28] Wang, Y., Yang, J., \& Yang, X. (2018). Challenges of the opening of frontier education in Yunnan Province: Based on the investigation of Myanmar students in Dehong Dai and Jingpo Autonomous Prefecture. Journal of Dali University, 3 (3), 119-123.

[29] Fang, T., \& He, Y. (2017). The paradox of "dropouts due to wealthier conditions" in the development of ethnic minorities' education-Taking the economic forests in the border area of
Yunnan Province as a case study. Journal of Ethnology, 8 (4), 45-53.

[30] He, Y., \& Gao, H. (2011). On the cross-border education and the cross-border ethnic education in Yunnan. Journal of Yunnan Nationalities University, 28 (2), 5-9.

[31] Gao, Z., \& Sha, L. (2014). Religious demand and cross-border mobility - A case study of cross-border ethnic Christianity in Sino-Burmese borderlands. World Religions Research, 6, $108-116$.

[32] Xu, Z., \& Liu, H. (2016). Historical patterns and stage features in the cross-border Christianity interactions in Sino-Burmese border areas. World Religion Culture, 3, 78-89.

[33] Qiao, G., \& Wang, Yu. (2015). Research on cross-border education in frontier elementary schools in Ruili from cultural reproduction perspective. Journal of Puer College, 2, 125-129. 